\title{
China Focuses on Rural Informatization
}

In the introduction to a new World Bank Report: Rural Informatization in China, Mohsen Khalil, Director of the Global Information and Communications Department, World Bank Group stated: "Over the last decade, informatization - the transformation of an economy and society through the effective deployment of information and communications technologies in business, social and public functions - has been a significant phenomenon in China. Launched in the coastal urban areas, the process of informatization has rapidly expanded to the inner rural areas, where over half of the country's population lives. This means that over 700 million previously unserved rural consumers can now access public services and information," www.publicationsannouncement@worldbank.org.

"The Government of China continues to advance the informatization process as part of its strategy to reduce rural poverty and improve the living conditions of farmers. Finding sustainable models that can be scaled will be critical for China to achieve equitable development across regions, and to reduce the rural-urban divide," Khalil observed. The report is composed of six chapters that present the present situation in China, rural informatization initiatives and organizational models, lessons from international experience, challenges for rural informatization in China, and a number of recommendations. The report summarizes the current situation as regards rural informatization in China.

China's has identified rural informatization as key to achieving nationwide growth and improving people's capacity for participating in new economic domains. In addition to specific informatization goals in the 11th Five Year Plan, the related deployment strategies such as the State Informatization Development Strategy, 2006-2020 underscore the importance the government has accorded to rural informatization. Thus the growing gap between rural and urban areas has been a mounting area of concern, encouraging the development of a number of policies and initiatives to promote rural informatization and better equip all citizens for participation in the new global order.

Key development objectives and rural informatization in China include:

- Catching up with more advanced regions. Informatization could facilitate contacts and exchanges between China's central and western regions and more developed regions, allowing farmers and agro-business to obtain technologies and market information that enable them to make full use of their comparative advantages in developing new products and increasing trade, market share, and ultimately incomes. Furthermore, leading agro-businesses in developed regions can show small and low-value industries in less advanced regions how to improve their management and technological skills and market competitiveness reducing regional gaps.

- Integrating and modernizing the rural market economy. Most rural enterprises in rural China are small and private. Given their isolation and weak financial foundation, the market economy in rural areas remains underdeveloped. Better rural information infrastructure can provide market information, communication channels, and financial resources to farmers and rural economy to enter markets and increase their diversification and competitiveness. Such infrastructure can do so by facilitating better farming techniques, helping to choose crops to plant in response to market information, improving production and resource management (for example through geographic information systems), and reducing marketing costs and exploitation by intermediaries.

- Strengthening delivery of social and public services. Government information support systems should aim to capture timely, accurate, comprehensive data on local economies and social activities. One approach to improving public ser- 
vice delivery is to integrate information on rural economies, science and technology, education, health, social protection and other areas. The resulting common infrastructure and databases can then be shared across ministries and regions in support of rural delivery.

- Augmenting income and nonagricultural employment through diversification and increased productivity. With information, farmers are better equipped to make important decisions and learn about diversified employment opportunities. With the growing dependence on the service sector, rural economies could benefit from diversifying into providing local ICT-enabled extension services.

- Increasing the quality and relevance of information and the human capacity of the rural population. Access to relevant information can transform economic opportunities and improve livelihoods for rural households - especially the poor population and young people. Rural informatization not only directly affects economic development, but it also brings in modern ideas and forward looking mindsets from more advanced regions. This can pave the way for transformative ideas and beliefs, increasing rural, social and cultural capacities in rural areas.

- Enabling participation in formulating agricultural policies and strategies. National development strategies and policies try to involve key stakeholders and the broader public. It is not easy to involve organizations that represent the rural poor. In recent years, ICT has been used to engage thousands of rural people in developing countries to deliberate policies. The spread of ICT in rural areas makes this type of participatory approach more feasible for dialogue on agricultural policy.

With the increased priority accorded to informatization by the Chinese government, numerous initiatives by the government and telecom providers have resulted in a steady increase in the coverage of information infrastructure - including fixed line telephony, mobile telephones, radio and television and the Internet. Such initiatives provide an adequate foundation for informatization especially in rural areas.

\section{Fixed Line Telephony}

The Ministry of Information Industry has been active in encouraging the spread of fixed line telephony under its initiative to extend telephone coverage to every village. Under this project, in 2007 the six main telecommunications providers shared obligations based on geographic divisions and extended telephone services to 3,759 administrative villages that previously had no access. Today 99.5 percent of administrative villages have fixed line coverage.

\section{Mobile Telephony}

By 2007 China Mobile launched a rural information network in 2006 in which it has invested 350 million RMB (US\$51 million). The company will enhance this network through further construction in Chongqing, turning it from the center of the western region into the national center, and raise the network's operationsupporting ability to promote its sustainable development. By 2009 China Mobile plans to invest 450 million RMB (US\$66 million) to optimize the functions of the network, which offers better services to 800 million farmers across China.

\section{Radio and Television}

Efforts to extend radio and television coverage have been led by the State Administration of Radio, Film and Television, which in 2002 launched a project to extend telecommunications to every village as part of the 10th Five Year Plan. By June 2006 investment in covering administrative villages totaled about 3.64 billion RMB (US\$532 million. This project has reached about 117,000 administrative villages with electricity but no telecommunications - known as "blind" villages - and repaired services in 15,000 "back to the blind" villages (those who had lost existing services), providing nearly 100 million farmers with access to radio and television. As a result rural ownership of personal television has steadily increased, reaching 89 percent of households in 2006.

\section{Internet}

China's Internet market is migrating from narrowband to broadband access. China Telecom and China Netcom, the two main fixed-line operators, have laid out plans for extending broadband access under an initiative to reach every household with fiber optics and started to replace copper cables. China Netcom will 
invest 15 billion RMB (US\$2.2 billion) to replace copper cables with fiber optics in the new network, which will launch in 2008 and is expected to be completed in three to five years.

In 2008 China Netcom planned to implement this initiative in the medium-size and large cities of $10 \mathrm{se}$ lected provinces (regions, metropolitans) in northern China, the company's territory Henan, Shandong, Tianjin have already begum implementing a pilot project to reach every village with fiber optics.
The number of broadband users in China has grown rapidly in recent years. According to data from the China Internet Network Information Center, the country had 210 million Internet in 2007 - lagging behind the United States by just 5 million. At that time 78 percent of China's Internet users were broadband users. Still a significant differences remain between urban Internet users in China, accounting for 27 percent of the urban population. By contrast 53 million rural Internet users accounted for just 7 percent of the rural population. 